\title{
Mathematical Modeling of Double Passive Automobile Suspension System in Proton Preve Car Model
}

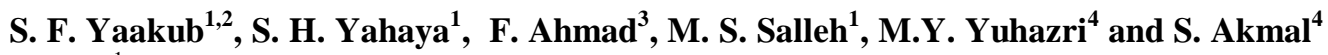 \\ ${ }^{1}$ Faculty of Manufacturing Engineering, Universiti Teknikal Malaysia Melaka, \\ 76100 Durian Tunggal, Melaka, Malaysia. \\ ${ }^{2}$ Jabatan Pendidikan Politeknik dan Kolej Komuniti, 62100, Putrajaya, Malaysia. \\ ${ }^{3}$ Faculty of Mechanical Engineering, Universiti Teknikal Malaysia Melaka, \\ 76100 Durian Tunggal, Melaka, Malaysia. \\ ${ }^{4}$ Faculty of Mechanical and Manufacturing Engineering Technology, Universiti Teknikal Malaysia Melaka, \\ 76100 Durian Tunggal, Melaka, Malaysia. \\ Corresponding Author's Email: saifudin@utem.edu.my
}

\begin{abstract}
A car suspension is a system of spring or shock absorbers connecting the wheels and axles to the chassis of a vehicle. In this paper, a mathematical modeling of double passive quarter car model's suspension system is formulated. These models are solved numerically using the second order linear differential equations and the simulation of this modelling obtained from the graphical outputs using MATLAB software. The comparison for vertical displacement between the mathematical model and the experimental of double passive suspension system using Proton Preve car model is also conducted. The results showed the oscillation of vertical displacement for mathematical model and the experimental for double passive model are roughly the same pattern. Therefore, the mathematical modeling of double passive system can be further used to predict the behavior of the double passive suspension system since the model had a similar accuracy with the experimental based.
\end{abstract}

Key words : Double Passive, Suspension System, Proton Preve, Mathematical Modeling.

\section{INTRODUCTION}

Nowdays, technology is moving towards for the improvement. Automotive sector is one of the big steps towards the technological improvements, which is possible thorough creativity and innovation of young automobile enthusiasts [1]. Oyetunji et al. [2], mentioned that the approach of automobile part production indicates the potential performance of the components. However, the cost of achieving high automation in the automotive industries is very challenging. The perfect automotive suspension system can absorb road shocks rapidly and could return to its normal position slowly while maintaining optimal tire to road contact [3]-[5]. Ankita [6] identified that traditionally or passive automotive suspension systems are designed with three criteria which are load capacity, passengers' comfort and road handling.

Suspension is term given to the system of springs, shock absorbers and linkages that connects a vehicle to its wheels. Suspension systems serve a dual purpose which is contributing to the car's road holding/handling and braking for good active safety and driving pleasure, and keeping vehicle occupants comfortable and reasonably well isolated from road noise, bumps, vibrations, and others. It is essential for the suspension to keep the road wheel in contact with the road surface as much as possible, because all the forces acting on the vehicle do so through the contact patches the tires. A passive suspension system is an ordinary suspension system consists of a non-controlled spring and shocking-absorbing damper. The commercial vehicles today use passive suspension system to control the dynamics of a vehicle's vertical motion as well as pitch and roll [7]. In the engineering term, the suspension system can be categorized into passive, semi-active and active suspension system according to external power input to the system and/or a control bandwidth [8].

The aim of this study is to formulate the mathematical modeling of double passive suspension system by using Proton Preve car model. The performance for the double passive automobile suspension systems was evaluated by using the graph from Matlab software. This study concerns mainly to validate the mathematical modelling formulated for double passive automobile suspension system in Proton Preve car model. The comparison is made using the graph between the mathematical model and the experimental data from Proton Preve car model by employing Matlab software. A 
quarter car model of Proton Preve is used to find out the formula for the double passive automobile suspension systems.

The contribution of this study is obvious as the resulting outcomes can be capitalized as guidelines to identify the better automobile suspension systems. Many researches also have been done in this area to find the optimization improving of the ride comfort. Amin [9] has performed a detailed experimental work to determine the effects of road excitation on ride comfort. Several methods are used such as rotating square evolutionary operation (ROVOP), gradient based method, genetic algorithm and sequential search method to determine the ride comfort. Shirahatti [10] have used Genetic Algorithm to find minimum acceleration; road holding and the result were compared by using Simulink model. The performance of suspension systems between mathematical model and experimental for Proton Preve car model suspension systems has not been comprehensively studied. Recently, the passive suspension system has been researched thoroughly only to intelligence of the system itself and the mathematical model has not formulated. Comparison for oscillation of travel displacement against its time among mathematical model and experimental for passive suspension systems by using Proton Preve car are not study yet.

This paper is organized as follows: The introduction about passive automobile suspension systems are studied in Section 1. The new mathematical modelling of passive automobile suspension systems is established in Section 2. Section 3 derives the solution of mathematical model for double passive Proton Preve suspension systems. The analysis of displacement compared with time travel for passive and experimental systems addressed in Section 4. Finally, this study is summarized in Section 5.

\section{PASSIVE SUSPENSION SYSTEM}

A passive suspension system is an ordinary suspension system consists of a non-controlled spring and shocking-absorbing damper. Automobile suspension system is designed to absorb and minimize the forces experienced by the wheels of a vehicle. The maximum displacement and acceleration are needed to design suspension system [11]. The commercial vehicles today use passive suspension system to control the dynamics of a vehicle's vertical motion as well as pitch and roll. Passive indicates that the suspension elements cannot supply energy to the suspension system. Common fluids such as water, ethylene glycol, and heat transfer oil play an important role in many industrial processes such as power generation, heating or cooling processes, chemical processes, and microelectronics. However, these fluids have relatively low thermal conductivity and thus cannot reach high heat exchange rates in thermal engineering devices [12].
The passive suspension system controls the motion of the body and wheel by limiting their relative velocities to a rate that gives the desired ride characteristics [13]. This is achieved by using some type of damping element placed between the body and the wheels of the vehicle, such as hydraulic shock absorber.

In this section, the passive automobile suspension system formulated from a simple car of Ford Scorpio model. The model uses spring ( $k$ ), damper $(c)$ that is connected with the wheel mass $(m)$. The model is illustrated in Figure 1 .

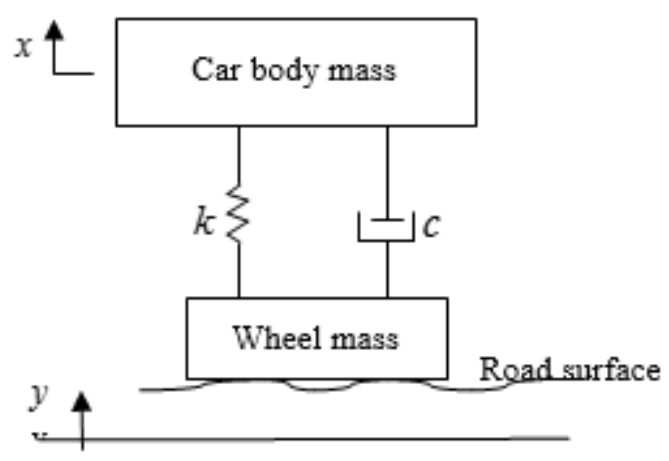

Figure 1: Simple Model Car Suspension

Newton's second law of motion in a vertical direction applied to derive the mathematical equations for describing the motion. By assuming the car body and the wheels are moving vertically upwards with the spring and damper expressed as

$$
X(t)=x-y
$$

where

$X(t)$ is an extension of the spring;

$x$ is the vertical displacement of the car body above its equilibrium position;

$y$ is the vertical displacement of the wheel (due to the road surface measured with respect to some fixed horizontal line).

Springs provide a simple mechanical disconnected between the shocking force sustained by the vehicle's wheels and axles and the body of the car with the passenger inside. Hooke's law accurately models for the physical properties of common mechanical springs or small changes in length. In mechanics and physics, Hooke's law of elasticity is an approximation that states that the extension of a spring is in direct proportion with the load added to it as long as this load does not exceed the elastic limit. A mechanical element for spring can be deformed by an external force when the force applied on it. The relation between the acting force $f$ and the displacement 
S. F. Yaakub et al., International Journal of Emerging Trends in Engineering Research, 8(10), October 2020, $7082-7086$

$x$ is

$$
F_{s}=k x(t)
$$

and the spring force gives as

$$
F_{s}=k(x-y)
$$

where $F_{S}$ is a force of the spring, $k$ is a constant parameter and $x-y$ is an extension of the spring. Shock absorbers provide damping of the motion experienced by the vehicle's wheels as the move up and down over uneven road surface. A hydraulic system used to provide resistance to the kinetic energy produced by the wheels. The damping force often being a model when the viscosity or drag is not negligible in a system. For this passive system, its only deal with the linear damping force. Given the damper force such as

$$
F_{d}=c v
$$

where $F_{d}$ is resisting force for damper, $c$ is damping coefficient and $v$ is relative velocity of the housing and the piston.

$$
v=d X(t) / d t=d(x-\mathrm{y}) / \mathrm{dt}
$$

where

$X(t)$ is an extension of the spring;

$x$ is the vertical displacement of the car body above its equilibrium position;

$y$ is the vertical displacement of the wheel (due to the road surface measured with respect to some fixed horizontal line).

The first order differential equation for Equation (5) becomes

$$
v=x^{\prime}(t)-y^{\prime}(t)
$$

Figure 1 can also be modeled and simplified as in Figure 2.

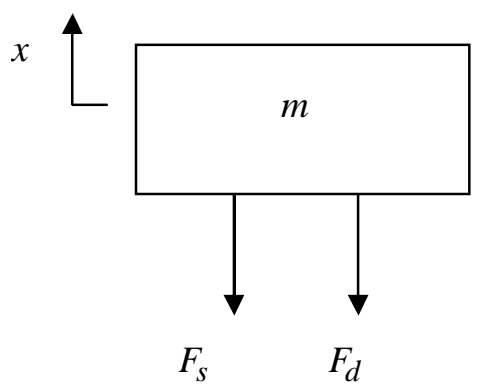

Figure 2: Damper and Spring Forces in Car Body Model
Figure 2 implies the Newton law of motion. Newton law of motion is physical laws which provide relationships between the forces acting on a body and the motion of the body. In this study, the mathematical model for motion is provided by Newton's second law. Newton's second law (law of resultant force) defined as the rate of change of momentum of a body is proportional to the resultant force acting on the body and is in the same direction. The Newton's second law of motion can be denoted

$$
f=m a
$$

where $f$ is the force, $m$ is the mass and $a$ is the acceleration.

Newton's second law also can be written as a second order of ordinary differential equation such as

$$
m^{\prime \prime}(t)=-F_{s}(t)-F_{d}(t)
$$

Jamaluddin [14] denoted the road surface profile as a sinusoidal curve shown in Figure 3.

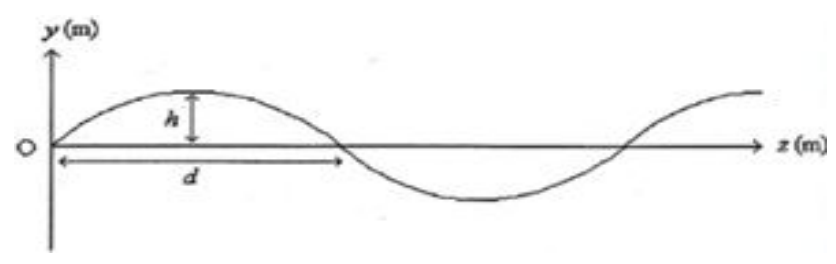

Figure 3: Sinusoidal Road Surface Profile

The sinusoidal road surface is described as

$$
y=h \sin (\alpha z)
$$

where $h$ is the amplitude of the sinusoidal, $y$ is the vertical displacement of the wheel due to the road surface measured with respect to some fixed horizontal datum line and $z$ is horizontal displacement. In the road profile, assuming the car is travelled with an average horizontal speed, $V$ as

$$
z=V t
$$

Therefore,

$$
y(t)=h \sin ((\pi V t) / d)
$$

Differentiate of $y(t)$ to have

$$
y^{\prime}(t)=h((\pi V) / d) \cos ((\pi V t) / d)
$$


S. F. Yaakub et al., International Journal of Emerging Trends in Engineering Research, 8(10), October 2020, $7082-7086$

\section{DEVELOPMENT OF DOUBLE PASSIVE SUSPENSION SYSTEM}

In order to verify the proposed model therefore, the parameter values of Proton Preve Car are then employed. The following parameters of the Proton Preve car model are such as

$$
\begin{aligned}
& m=290 \mathrm{~kg} ; k=16812 \mathrm{Nm}^{-1} ; \\
& c=1000 \mathrm{Nsm}^{-1} ; V=14 \mathrm{~ms}^{-1} ; \\
& d=2 \mathrm{~m} ; h=0.1 \mathrm{~m} .
\end{aligned}
$$

From Equation (8), then

$$
\begin{aligned}
& m^{\prime \prime}(t)=-k(x-y)-c\left(x^{\prime}(t)-y^{\prime}(t)\right) \\
& m^{\prime \prime}(t)+c x^{\prime}(t)+k x(t)=k y+c y^{\prime}(t)
\end{aligned}
$$

Substitute Equation (11) and Equation (12) to yield

$$
\begin{aligned}
& m^{\prime \prime}(t)+c x^{\prime}(t)+k x(t)=k \cdot h \sin ((\pi v t) / d) \\
& +c \cdot h((\pi v) / d) \cos ((\pi v t) / d)
\end{aligned}
$$

Then we have

$$
\begin{aligned}
& 290 x^{\prime \prime}(t)+1000 x^{\prime}(t)+16812 x(t)=1681.2 \sin (7 \pi t)+ \\
& 700 \pi \cos (7 \pi t)
\end{aligned}
$$

Employ the nonlinear form to solve Equation (16) such as

$$
X(t)=X_{p}(t)+X_{c}(t)
$$

where $X_{p}$ is a general particular solution and $X_{c}$ is a complementary solution.

Solution for $X_{p}$ and $X_{c}$ obtained as

$$
\begin{gathered}
X_{p}(t)=e^{-1.7724 t}[a \cos (7.416) t+b \sin (7.416) t] \\
X_{c}=-0.0196 \cos (7 \pi t)-0.0101 \sin (7 \pi t)
\end{gathered}
$$

Substitute Equations (18) and (19) into Equation (17) produces

$$
\begin{aligned}
& X(t)=e^{1.724 t}[a \cos (7.416) t+b \sin (7.416) t]- \\
& 0.0196 \cos (7 \pi \mathrm{t})-0.0101 \sin (7 \pi \mathrm{t})
\end{aligned}
$$

The following initial conditions are applied to determine $a$ and $b$ :

$$
X(0)=0 \& X^{\prime}(0)=0
$$

Therefore,

$$
a=0.0196 \& b=0.345
$$

Substitute the values from Equation (20) into Equation (18) depicted as

$$
\begin{aligned}
& X(t)=e^{-1.724 t}[0.0196 \cos (7.416) t+0.035 \sin (7.416) t] \\
& -0.0196 \cos (7 \pi t)-0.0101 \sin (7 \pi t)
\end{aligned}
$$

\section{RESULTS AND DISCUSSION}

In this paper, the measurement of displacement denoted by $x(t)$ is the main focus. Then the $x(t)$ continued by plotting the graph using Matlab Software. For plotting the passive suspension systems, use time from 0 to 4 seconds. The assessment for validate the model is based on the experimental data for Proton Preve car model.

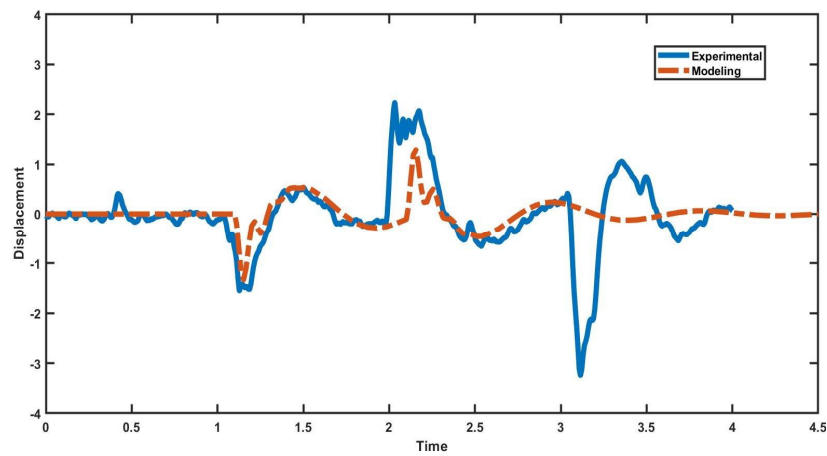

Figure 4: Displacement $(x)$ against Time $(t)$ for Proton Preve Car using Passive System

Figure 4 indicates the oscillation of the car body's vertical displacement is damping for Proton Preve car. The line indicates for passive systems using the data from experimental and the dash-dot indicate passive systems using the model. At $0.02 \mathrm{~m}$, the displacement is maximum and minimum at $-0.035 \mathrm{~m}$ for experimental. The maximum displacement for modeling suspension systems is $0.01 \mathrm{~m}$ and minimum at $-0.015 \mathrm{~m}$. For stability, both of the graph becomes 
S. F. Yaakub et al., International Journal of Emerging Trends in Engineering Research, 8(10), October 2020, $7082-7086$

stable at $4 \mathrm{~s}$. The maximum and minimum displacement happened when the suspension system shrinking and expanding to stabilize the car. Since the graph behavior are the same therefore the accuracy of the both models are the same. The mathematical modeling can be further employed for predicting this model.

\section{CONCLUSION}

The mathematical model of double passive suspension systems has been successfully developed and applied for Proton Preve car. Second-order differential equation are the employed methods during mathematical modelling development and analyzed via Matlab software. In this study, the suspension travel limit of car's displacement and stability of systems are validated using the data from experimental of Proton Preve car.

From the result, displacement of a double passive model showed the similar behaviour with experimental. Therefore, the developed model proven can be used as a passive model for all of automobile car model and also for predicting the model for future since the accuracy remained the same.

Further investigation and experimentation into double semi-active automobile suspension systems is strongly recommended. It would be interesting to assess the combination of semi-active suspension systems such as electromagnetic and Magneto-Rheological for the greater results in the control performance of the automobile suspension system.

\section{ACKNOWLEDGEMENT}

This study was supported by Universiti Teknikal Malaysia Melaka and Politeknik Malaysia. The authors greatly acknowledge anyone who has contributed for the helpful suggestions and comments.

\section{REFERENCE}

1. H. Ambashta, C. Mehndiratta, and N. Waghmare. Design of braking system for Go-kart, International Journal of Emerging Trends in Engineering Research, Vol. 5, no. 11, pp. 57-59, November 2017.

2. O. R. Oyetunji, W. A. Adesope, P. Ufokima, E. Y. Salawu, A. O.Araoyinbo, and F. A. Ishola. Design and fabrication of a pilot scale remote controlled electric car using additive manufacturing approach, International Journal of Emerging Trends in Engineering Research, Vol. 8, no. 7, pp. 3054-3057, July 2020.

3. R. E. Clark, D. S. Smith, and P. H. Mellor. Design optimization of moving-magnet actuators for reciprocating electro-mechanical systems magnetics, IEEE Transactions, pp. 3746-3748, 1995.
4. D. L. Trumper, W. J. Kim, and M. E. Williams. Design and analysis framework for linear permanent-magnet machines industry applications. IEEE Transactions on Industry Applications, Vol. 32, no.2, pp. 371-379, 1996.

5. Z. Q. Zhu, and D. Howe. Magnet design considerations for electrical machines equipped with surface mounted permanents, Proceedings of the $13^{\text {th }}$ International Workshop Rate-earth Permanent Magnets Application, pp. 151-160, 1994.

6. R. Ankita, Bhise, G. D. Rutuja, R. N. Yerrawar, A. C. Mitra, and R. R. Arakerimath. Comparison between passive and semi-active suspension system using matlab/simulink, IOSR Journal of Mechanical and Civil Engineering, vol. 13, no. 4, pp. 01-06, 2016.

7. P. Sathishkumar, J. Jancirani, J. Dennie and S. Manikandan. Mathematical modelling and simulation quarter car vehicle suspension, International Journal of Innovative Research in Science, Engineering and Technology, Vol. 3, pp. 1280-1283, 2014.

8. N. M. Suaib. Modelling and control of active suspension using PISMC and SMC, Ph. D. Thesis, Fac. of Elect. Eng., Universiti Teknologi Malaysia, 2008.

9. A. Z. M. Amin, S. Ahmad and Y. S. Hoe. Electromagnetics car suspension system, Journal of Science and Technology, Vol. 9, no.40, pp. 01-04, 2016.

10. A. Shirahatti, P. S. S. Prasad, P. Panzade and M. M. Kulkarni. Optimal design of passenger car suspension for ride and road holding, Journal of the Brazilian Society of Mechanical Science \& Engineering, Vol. 30, no.1, pp. 66-76, 2008.

11. B. A. Balasaheb, and A. P. Kokare. Performance testing of shock absorber on single DOF spring mass damper system using MATLAB, International Journal of Emerging Trends in Engineering Research, Vol. 4, no. 9, pp. 8-14, September 2016.

12. G. I. Egu, U. C. Okonkwo, I. P. Okokpujie, and N. E. Udoye. Effects of slenderness ratio on the critical flow velocity of fluid, International Journal of Emerging Trends in Engineering Research, Vol. 8, no. 9, pp. 6505-6511, September 2020.

13. S. F. Yaakub, S. H. Yahaya, F. Ahmad, M.S. Salleh, and A.R.M. Warikh. A comprehensive review on the related models in magneto-rheological automobile suspension system, International Journal of Engineering Research and Technology, Vol. 13, no. 7, pp. 1700-1708, 2020.

14. J. Jamaluddin. Mathematical modelling and simulation of quarter car suspension system, Master Thesis, Faculty of Science, Universiti Teknologi Malaysia, 2015. 